\title{
Platelet-Derived Growth Factor BB Influences Muscle Regeneration in Duchenne Muscle Dystrophy
}

\author{
Patricia Piñol-Jurado, ${ }^{{ }^{\dagger}}$ Eduard Gallardo, ${ }^{{ }^{\dagger}}$ Noemi de Luna, ${ }^{* \dagger}$ Xavier Suárez-Calvet, ${ }^{* \dagger}$ Carles Sánchez-Riera, ${ }^{*}$ \\ Esther Fernández-Simón, ${ }^{* \dagger}$ Clara Gomis, ${ }^{\dagger \dagger}$ Isabel Illa, ${ }^{* \dagger}$ and Jordi Díaz-Manera* ${ }^{* \dagger}$
}

From the Neuromuscular Disorders Unit, * Department of Neurology, Universitat Autònoma de Barcelona, Hospital de la Santa Creu i Sant Pau, Barcelona; the Network Research Center in Rare Diseases, ${ }^{\dagger}$ Barcelona; and the Department of Neurology, ${ }^{\ddagger}$ Hospital Universitario de la Fe, Valencia, Spain

\author{
Accepted for publication \\ April 5, 2017. \\ Address correspondence to \\ Jordi Díaz-Manera, M.D., \\ Ph.D., Neuromuscular Disor- \\ ders Unit, Department of \\ Neurology, Hospital de la Santa \\ Creu I Sant Pau, C/Sant Antoni \\ $M^{\text {a }}$ Claret 167, Barcelona \\ 08025, Spain. E-mail: jdiazm@ \\ santpau.cat.
}

\begin{abstract}
Duchenne muscular dystrophy (DMD) is characterized by a progressive loss of muscle fibers, and their substitution by fibrotic and adipose tissue. Many factors contribute to this process, but the molecular pathways related to regeneration and degeneration of muscle are not completely known. Plateletderived growth factor (PDGF)-BB belongs to a family of growth factors that regulate proliferation, migration, and differentiation of mesenchymal cells. The role of PDGF-BB in muscle regeneration in humans has not been studied. We analyzed the expression of PDGF-BB in muscle biopsy samples from controls and patients with DMD. We performed in vitro experiments to understand the effects of PDGF$\mathrm{BB}$ on myoblasts involved in the pathophysiology of muscular dystrophies and confirmed our results in vivo by treating the $m d x$ murine model of DMD with repeated i.m. injections of PDGF-BB. We observed that regenerating and necrotic muscle fibers in muscle biopsy samples from DMD patients expressed PDGF-BB. In vitro, PDGF-BB attracted myoblasts and activated their proliferation. Analysis of muscles from the animals treated with PDGF-BB showed an increased population of satellite cells and an increase in the number of regenerative fibers, with a reduction in inflammatory infiltrates, compared with those in vehicle-treated mice. Based on our results, PDGF-BB may play a protective role in muscular dystrophies by enhancing muscle regeneration through activation of satellite cell proliferation and migration. (Am J Pathol 2017, 187: 1814-1827; http://dx.doi.org/10.1016/j.ajpath.2017.04.011)
\end{abstract}

Duchenne muscular dystrophy (DMD) is a genetic disorder produced by mutations in the dystrophin gene. ${ }^{1}$ Patients develop muscle weakness that progresses over years, producing severe impairment of the patient's mobility and requiring help for all daily life activities. This clinical progression is the result of a continuous loss of muscle fibers and their substitution by fibrotic and fat tissue. ${ }^{2}$ The persistent damage of muscles that occurs in muscular dystrophy exhausts the pool of satellite cells - the main protagonists of muscle regeneration-and enhances the proliferation of fibro-adipogenic progenitor cells. ${ }^{2,3}$ Several growth factors and cytokines have been related to the processes of muscle degeneration and regeneration. These growth factors include transforming growth factor $\beta$; IL-1b; IL-6; tumor necrosis factor $\alpha$; and, more recently, plateletderived growth factors (PDGFs).,
The family of PDGFs participates in several biological functions, such as cell proliferation, migration, and differentiation. ${ }^{6}$ All PDGFs are secreted as dimers of disulfide polypeptide chains by platelets, monocytes, endothelial cells, and other cell types. ${ }^{7}$ There are five types of PDGF dimers: the homodimers PDGF-AA, -BB, -CC, and -DD and the heterodimer PDGF-AB. Once released, these factors have a paracrine effect on surrounding PDGF receptor

Supported by the Fundacion Isabel Gemio, Mutua Madrileña de Seguros, Duchenne Parent Project Spain, Spanish Ministry of Health Fondo de Investigaciones Sanitarias (FISS) grants PI15/01822 (J.D.-M.) and PI12/ 02291 (E.G.), Myositis Association of the United States fellowship grant (X.S.-C.), Fundación Universia (C.S.-R.), and Fundació Caixa Enginyers (C.S.-R.).

Disclosures: Nintedanib was supplied by Boehringer Ingelheim. 
(PDGFR)-positive cells. ${ }^{6}$ Mesenchyme-derived cells, such as satellite cells or pericytes, express PDGFR. ${ }^{8,9}$ The two PDGFR isoforms, $\alpha$ and $\beta$, each are capable of homo- or heterodimerization in the presence of PDGF. PDGF-AA and -CC activate PDGFR $\alpha \alpha$ homodimers, whereas PDGF-BB and -DD activate PDGFR $\beta \beta$ homodimers, in vivo. ${ }^{10}$ Once activated, PDGFR acquires tyrosine kinase activity, triggering multiple downstream pathways, such as Ras/ mitogen-activated protein kinase (MAPK), phosphoinositide 3-kinase/protein kinase B (Akt), phospholipase $\mathrm{C} \gamma /$ protein kinase $\mathrm{C}$, or STATs that finally regulate gene expression. $^{7}$

PDGFs play a crucial role in early developmental processes, such as the formation of the neural crest, the spread of cells into growing tubular structures (eg, vessels or brachial pouches), and the proliferation of tissue-specific stromal cells (eg, dermal or renal fibroblasts). ${ }^{11-13}$ In adult humans, increased PDGF signaling has been related to several diseases, examples being atherosclerosis, cancer, and fibrosis. ${ }^{14-16}$

The role of PDGFs in normal or pathologic skeletal muscle is not completely understood. It is known that PDGF-AA and -BB are secreted by muscle fibers in DMD patients. ${ }^{17}$ There is evidence to support a profibrotic role of PDGF-AA in muscle dystrophies: i) perivascular PDGFR $\alpha$ fibro-adipogenic progenitor cells proliferate after a muscle injury ${ }^{18,19}$; ii) skeletal muscles from knock-in mice with PDGFR $\alpha$-activating mutations in which there is a constitutive expression of PDGFR $\alpha$, showed increased fibrotic tissue $^{20}$; and iii) treatment of $m d x$ mice in a murine model of DMD - with PDGFR $\alpha$ antagonists-reduces skeletal muscle fibrosis. ${ }^{21,22}$

In contrast, the role of PDGF-BB in skeletal muscle has not been clarified. Endothelial cells in healthy muscle express PDGF-BB, acting as a ligand for PDGFR $\beta$ pericytes, which confer structural support to the vessel wall. ${ }^{23}$ The role of PDGF-BB after muscle damage is unknown. It has been reported that PDGF-BB influences the proliferation of satellite cells in several animal species. ${ }^{24,25}$ Based on this previous finding, some authors have suggested that PDGF$\mathrm{BB}$ could be relevant in muscle regeneration in patients with muscle diseases, but this concept has not been demonstrated. ${ }^{26}$

Our aim was to study the possible role of PDGF-BB in muscle regeneration through a series of in vitro and in vivo experiments.

\section{Materials and Methods}

\section{Muscle Biopsy}

Muscle biopsies were performed as part of the diagnostic process in patients who visited the Neuromuscular Disorders Unit at Hospital de la Santa Creu i Sant Pau (Barcelona, Spain). We studied the expression of PDGF-BB in muscle biopsy samples from patients with genetically confirmed
DMD $(n=5)$ and from patients undergoing orthopedic surgery but who were otherwise healthy (controls; $n=5$ ). All participants signed an informed-consent form, and all of the procedures were in accordance with the principles set forth in the Declaration of Helsinki.

\section{Immunofluorescence and Western Blot}

Muscle samples were frozen in liquid nitrogen-cooled isopentane, and serial 7-mm sections were cut with a cryostat (Leica Microsystems, Wetzlar, Germany).

Cell cultures were washed three times with phosphatebuffered saline and fixed with $4 \%$ paraformaldehyde at $4{ }^{\circ} \mathrm{C}$ for 10 minutes. Cells and tissue sections were processed for microscopic evaluation as previously described. ${ }^{27}$ Primary antibodies used in the experiments were rabbit anti-CD56 (Abcam, Cambridge, UK), rabbit anti-PDGF-BB (Santa Cruz Biotechnology, Dallas, TX), mouse anti-human embryonic myosin heavy chain (Novocastra, Newcastle on Tyne, UK), mouse anti-murine embryonic myosin heavy chain (Hybridoma Bank, Iowa City, IA), rabbit antiPDGFR $\beta$ (Cell Signaling Technology, Danvers, MA), mouse anti-CD4 (Dako North America, Carpinteria, CA), mouse anti-CD8 (Dako), mouse anti-CD68 (Dako), rabbit anti-collagen I (Abcam), rabbit anti-neural/glial antigen 2 chondroitin sulfate proteoglycan (EMD Millipore, Billerica, MA), mouse anti-desmin (Novocastra), mouse anti- $\alpha$ smooth muscle actin (Sigma-Aldrich, St. Louis, MO), mouse anti-paired box protein (Pax) 7 antibody (Hybridoma Bank), rat anti-laminin (Abcam), and the lectin Ulex europaeus (Vector Laboratories, Burlingame, CA). Appropriate Alexa-conjugated secondary antibodies were used.

Western blot analysis of cell cultures was performed as previously described. ${ }^{23}$ We extracted proteins from the cell pellets with a buffer containing $125 \mathrm{mmol} / \mathrm{L}$ Tris, $4 \%$ SDS, $4 \mathrm{M}$ urea, 5\% mercaptoethanol, $1 \%$ glycerol, bromophenol blue $0.0002 \%$, and protease inhibitor cocktail (Sigma-Aldrich). The antibodies used for Western blot analysis were mouse anti-phospho-STAT-1 and mouse anti-STAT-1 (Santa Cruz Biotechnology); rabbit anti-p44/42 MAPK (Erk1/2), rabbit anti-phospho-p44/42 MAPK (Erk1/2) (Thr202/Tyr204), rabbit anti-Akt, and mouse antiphospho-Akt (Ser473) (Cell Signaling Technologies); rabbit anti-collagen I (Abcam); and mouse anti-glyceraldehyde3-phosphate (Sigma-Aldrich).

\section{Isolation of Satellite Cells from Human Muscle Biopsy Samples}

Human satellite cells were isolated from the muscle biopsy samples of patients with DMD and controls $(n=3$ per group) as previously described. ${ }^{28}$ Briefly, muscle biopsies were minced into 1- to 2-mm pieces, transferred onto collagen type I (Sigma-Aldrich) coated dishes, and incubated in proliferating medium at $37^{\circ} \mathrm{C}, 5 \% \mathrm{CO}_{2}$, and $5 \% \mathrm{O}_{2}$. Proliferating medium consisted of a mixture of Iscove 
Dulbecco's modified Eagle's medium and M-199 medium (both from Lonza, Verviers, Belgium), in a 3:1 ratio, supplemented with $15 \%$ fetal bovine serum (FBS; Lonza), $2 \mathrm{mmol} / \mathrm{L}$ L-glutamine (Lonza), $5 \mathrm{ng} / \mathrm{mL}$ basic fibroblast growth factor (PeproTech, Rocky Hill, NJ), and 1\% penicillin-streptomycin (Lonza). After 5 to 7 days, cells started to sprout from the muscle explants. We isolated myoblasts using anti-CD56-coated microbeads (Miltenyi Biotec, Gladbach, Germany) and confirmed that the purity of the samples was $>95 \%$ performing immunofluorescence (IF) with antibodies anti-CD56 (Becton, Dickinson and Company, BD Biosciences, San Jose, CA) and anti-desmin (Leica Biosystems, Newcastle, UK) (Supplemental Figure S1). All experiments performed with myoblasts were repeated with the cells isolated from all patients $(n=3)$ and were replicated in triplicate.

\section{Culture Studies: Myotubes and Wounding Assays}

To obtain myotubes, human myoblasts were seeded at a density of 2500 cells $/ \mathrm{cm}^{2}$ using growth medium containing Dulbecco's modified medium/M-199 (3:1), 1\% glutamine, $15 \%$ FBS, and $1 \%$ penicillin-streptomycin. Once myoblasts were confluent, we substituted this medium with a differentiation medium containing $2 \%$ FBS.

Several membrane-wounding assays were used for damaging myotubes: i) incubation with $0.25 \mathrm{mmol} / \mathrm{L}$ SDS for 2 minutes, followed by two washes with Hanks' balanced salt solution 1X (Lonza); ii) incubation with 5 $\mu \mathrm{mol} / \mathrm{L}$ ionomycin (Sigma-Aldrich) for 5 minutes, followed by two washes with Hanks' balanced salt solution 1X; and iii) incubation of plates with $50 \mathrm{mg}$ of glass beads in Hanks' balanced salt solution $1 \mathrm{X}$ medium (Sigma-Aldrich) on a shaker for 5 minutes.

After damage, myotubes were incubated with Hanks' balanced salt solution $1 \mathrm{X}$ medium for 10,20 , and $30 \mathrm{mi}-$ nutes. We measured the concentration of PDGF-BB in the supernatants using enzyme-linked immunosorbent assay (Human PDGF-BB Quantikine enzyme-linked immunosorbent assay; R\&D Systems, Minneapolis, MN) following the manufacturer's instructions. To measure the concentration of creatine kinase, supernatants were concentrated using Centricon Plus filter devices with a $30-\mathrm{kDa}$ molecular weight cutoff (EMD Millipore) according to the manufacturer's protocol. The samples obtained were analyzed in the Biochemistry Laboratory at Hospital de la Santa Creu i Sant Pau using an architect ci16200 device (Abbott Laboratories, Abbott Park, IL).

\section{Culture Studies: Transwell Assays}

Myoblasts $(40,000$ cells in Opti-MEM I medium; Lonza) were deposited into Falcon insert $(3-\mu \mathrm{m}$-diameter pores; Becton, Dickinson and Company, Franklin Lakes, NJ) and placed on top of a well containing PDGF-BB concentrations of 10,50 , and $100 \mathrm{ng} / \mathrm{mL}$ (R\&D Systems); PDGF-BB incubated previously with blocking anti-PDGF-BB antibody (EMD Millipore) for 1 hour at $37^{\circ} \mathrm{C}$; or anti-PDGF$\mathrm{BB}$ antibody alone. The culture inserts were incubated at $37^{\circ} \mathrm{C}$ for 24 hours.

We counted the cells present in the lower well and in the membrane. Chemotaxis toward Opti-MEM I medium was considered as nonspecific. The cells present in the insert were fixed in ethanol $70 \%$ for 10 minutes and stained for 30 minutes with crystal violet (Sigma-Aldrich). After three washes with phosphate-buffered saline, filters were cut, mounted onto a slide, and observed with an Olympus microscope (Olympus, Center Valley, PA).

\section{Proliferation and Differentiation Assays}

To study the specific influence of PDGF-BB on cell proliferation, we plated myoblasts with a concentration of 3500 cells $/ \mathrm{cm}^{2}$ and cultured them in a basal medium that contained only $1 \%$ FBS. We added to the medium PDGF-BB (R\&D Systems) at a concentration of $10 \mathrm{nmol} / \mathrm{L}$. Fresh PDGF-BB was added to the medium every 24 hours for 6 days. In parallel we also analyzed cell proliferation on an FBSenriched medium; we plated myoblasts with a concentration of 3500 cells $/ \mathrm{cm}^{2}$ and cultured them in proliferating medium with or without PDGF-BB at a concentration of 10 $\mathrm{nmol} / \mathrm{L}$. For studying the effect of nintedanib (kindly donated by Boehringer Ingelheim, Rhein, Germany), a tyrosine kinase inhibitor that blocks the PDGFR, it was added to the proliferation medium at a concentration of $500 \mathrm{nmol} / \mathrm{L}$. For counting the cells, the cultures were trypsinized and cells were stained with Trypan Blue. Living cells were counted in a hemocytometer.

For studying differentiation, myotubes obtained from three different conditions were compared: control myotubes, myotubes obtained from a differentiation medium containing $10 \mathrm{ng} / \mathrm{mL}$ PDGF-BB, and myotubes obtained from a differentiation medium containing $50 \mathrm{ng} / \mathrm{mL}$ PDGF-BB. After 7 days in differentiation medium, cultures were fixed and we performed IF using antibodies against developmental myosin and DAPI for the nuclei. We obtained images of 10 areas randomly at $20 \times$ magnification from every culture condition with the microscope. Images were analyzed using Adobe Photoshop software version CS6 (Adobe Systems, San Jose, CA). We assessed the differentiation rate by counting the total number of nuclei present in developmental myosin-positive myotubes versus the total number of nuclei.

\section{Analysis of Intracellular Pathways}

For these experiments, myoblasts were cultured overnight with $1 \%$ FBS Dulbecco's modified Eagle's medium. The following day, cells were treated with $10 \mathrm{ng} / \mathrm{mL}$ PDGF-BB for 15 minutes and fixed. A group of cells were pretreated with the tyrosine kinase inhibitor nintedanib at a concentration of $500 \mathrm{nmol} / \mathrm{L}$ for 2 hours before PDGF-BB treatment. 


\section{RNA Extraction and Reverse Transcription}

Total RNA from cells was isolated using TRIzol following the manufacturer's instructions (InvitroGen, Carlsbad, CA) and stored at $-80^{\circ} \mathrm{C}$. RNA was reverse-transcribed from 1 $\mu \mathrm{g}$ of total RNA using the High-Capacity cDNA ReverseTranscription Kit (Applied Biosystems, Foster City, CA).

\section{qPCR}

Real-time quantitative (qPCR) of cDNA obtained from cells and tissues was performed using TaqMan Universal PCR Master Mix and the 7900HT Fast Realtime PCR System (both from Applied Biosystems). mRNA-specific fluorescein amidite-labeled primers/probe were purchased from Applied Biosystems for detecting cDNA from the following genes: PDGFB (Hs00966522_m1), MYODI (Hs00159528_m1), GAPDH (Hs99999905_m1), and Pdgfb (Mm00440677_m1). All experiments were performed in triplicate. Relative quantification was performed using the comparative $\mathrm{Ct}$ method, and all results were compared with the control samples for each treatment after normalization to an endogenous control (glyceraldehyde-3-phosphate) using the Relative Quantification Manager 7900 HT Fast RealTime PCR System software package version 2.4.1 (Applied Biosystems). Data in bar graphs are expressed as the means \pm SD of three independent samples.

\section{In Vivo Treatment with Notexin}

To investigate whether acute damage in skeletal muscle could increase the expression of PDGF-BB, we treated 5month-old C57 (control) and $m d x$ mice $(n=21$ per group) with a single i.m. injection of $50 \mu \mathrm{L}$ of Notexin Np (Latoxan S.A.S., Portes-lès-Valence, France) in the tibialis anterior muscles. We obtained the muscles injected at 1 and 24 hours and 3, 7, 15, and 21 days after damage (all time points, $n=$ 3 ) and compared them with those from nontreated animals $(n=3)$. We studied muscle structure using hematoxylin and eosin staining and analyzed the expression of PDGFBB using IF. In parallel, we quantified PDGF mRNA levels after damage as described in $q P C R$.

\section{In Vivo Treatment with Repeated Injections of PDGF-BB}

We used 8-month-old $m d x$ mice for the in vivo experiments. Four mice were treated with repeated i.m. injections of PDGF-BB. We injected $100 \mu \mathrm{L}$ at $50 \mathrm{ng} / \mathrm{mL}$ concentration, two times per week for 1 month in both tibialis anterior muscles. In parallel, four mice were treated with repeated i.m. injections of $100 \mu \mathrm{L}$ of saline solution (vehicle) using the same protocol. Four nontreated $m d x$ mice were used as controls. After treatment, the animals were sacrificed, and both tibialis anterior muscles were isolated for histologic analysis.
Using an Olympus microscope at $20 \times$ magnification, we obtained images of five random areas from each muscle biopsy sample. Images were analyzed using Adobe Photoshop software (Adobe Systems). To estimate the number of satellite cells, we performed double IF with the antibodies anti-Pax7 and anti-laminin, adding DAPI to identify the nuclei of the cells and myofibers. We counted the total number of $\operatorname{Pax} 7^{+}$cells and the total number of cells using DAPI. Moreover, we counted the total number of myofibers. The number of satellite cells was expressed as the ratio of $\mathrm{Pax}^{+}$cells to the total number of DAPI cells. We also analyzed the ratio of $\mathrm{Pax}^{+}$cells to the total number of fibers. A cross-sectional area of muscle fibers was analyzed using ImageJ software version 1.49 (NIH, Bethesda, MD; http://imagej.nih.gov.ij). To analyze inflammation in the muscles, we counted all $\mathrm{F} 4 / 80^{+}$cells present in the muscle sections. We expressed the result as the ratio of $\mathrm{F} 4 / 80^{+}$cells to the total number of DAPI nuclei. Finally we analyzed the collagen $\mathrm{I}^{+}$area using ImageJ software.

\section{Statistical Analysis}

We used the $t$-test to compare quantitative measures between samples, and analysis of variance to study repeated measures. Statistical significance was obtained at $P<0.05$. Statistical studies were performed with IBM SPSS Statistics software version 21 (IBM, Armonk, NY), and graphics were developed using DataGraph software version 4.0 (Visual Data Tools; http://www.visualdatatools.com/DataGraph).

\section{Results}

PDGF-BB Expression in Control Patients and in Patients with DMD

In muscle biopsy samples obtained from controls $(n=5)$, we observed that PDGF-BB was expressed in the vessel wall of capillaries but not in muscle fibers (Figure 1, A and C). Conversely, in muscle biopsy samples from DMD patients, PDGF-BB was expressed in vessels but also in the sarcoplasm of many muscle fibers (Figure 1, B and D) and in inflammatory infiltrates (Figure $1, \mathrm{~F}-\mathrm{N}$ ). We observed that both $\mathrm{CD}^{+} \mathrm{T}$ cells and $\mathrm{CD}^{+}{ }^{+} \mathrm{T}$ cells and also $\mathrm{CD} 8^{+}$cells (macrophages) expressed PDGF-BB. Satellite cells did not express PDGF-BB in vivo (Supplemental Figure S2). qPCR showed an increased expression of PDGF-BB in muscle biopsy samples from patients with DMD compared with those from controls (Figure 1E).

\section{PDGF-BB Is Expressed in Regenerating Fibers and Necrotic Fibers}

We observed that, in many cases, several PDGF-BB ${ }^{+}$ muscle fibers were pale on hematoxylin and eosin staining, suggesting that the fibers were necrotic (Figure 2, A and B). 

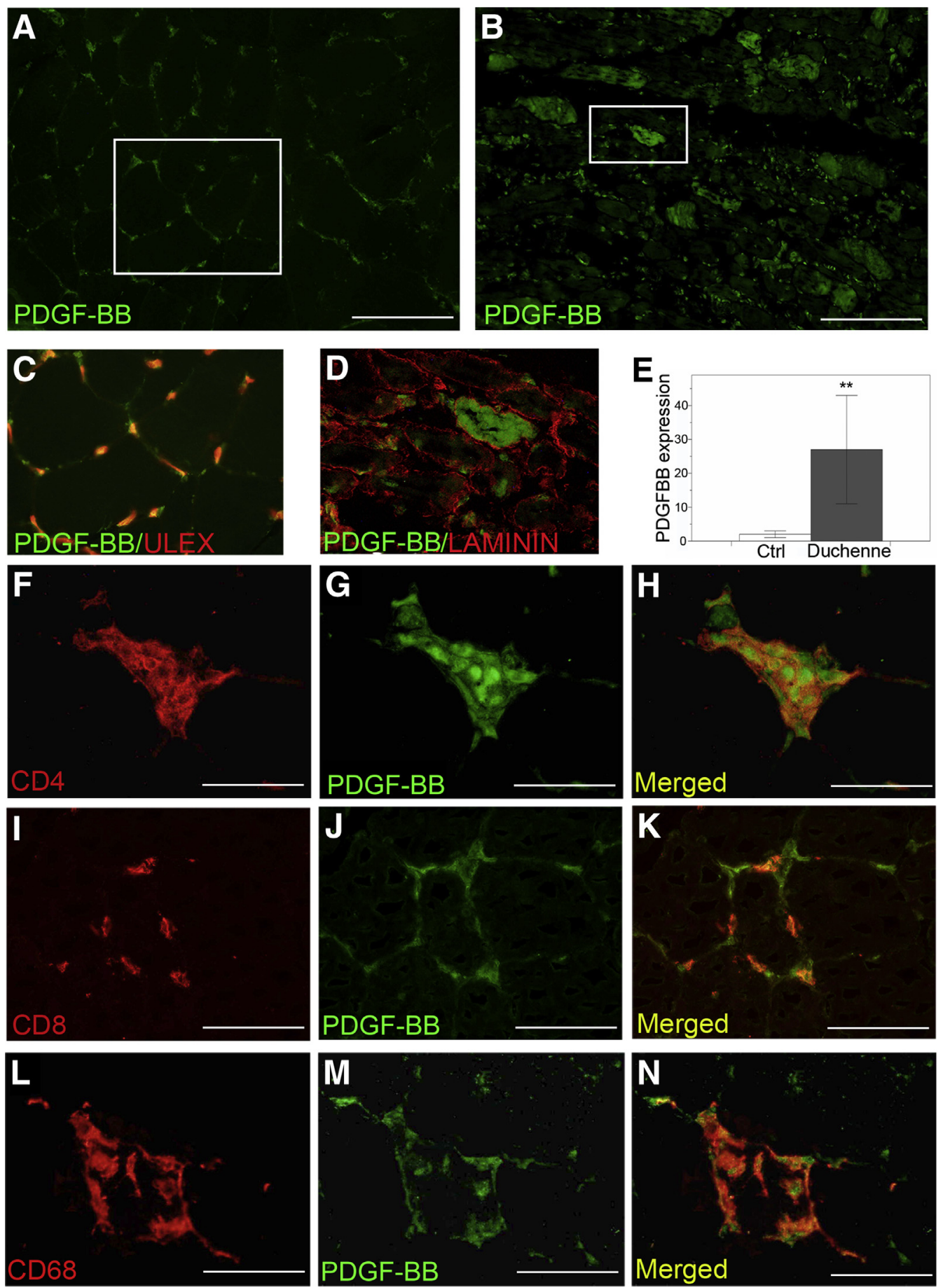

Figure 1 Platelet-derived growth factor (PDGF)-BB expression in healthy and pathologic muscle. The expression of PDGF-BB was studied using immunohistochemistry analysis in biopsy samples from healthy muscle (A and C) and in Duchenne dystrophic muscle (DMD; $\mathbf{B}$ and $\mathbf{D})$ ). In healthy muscle, PDGF-BB was expressed in the vessel wall (boxed region from $\mathbf{A}$ is detailed in $\mathbf{C}$ ). In muscle from DMD patients, PDGF-BB was also expressed in muscle fibers (boxed region from $\mathbf{B}$ is detailed in $\mathbf{D})$. The expression of PDGF-BB in inflammatory infiltrates in muscle biopsy samples from patients with $\mathrm{DMD}$ was detected: $\mathrm{CD}^{+}{ }^{+} \mathrm{T}$ cells $(\mathbf{F}-\mathbf{H}), \mathrm{CD}^{+} \mathrm{T}$ cells $(\mathbf{I}-\mathbf{K})$, and $\mathrm{CD}^{+} 8^{+}$macrophages $(\mathbf{L}-\mathbf{N})$; real-time quantitative PCR performed on cDNA obtained from control (Ctrl) muscle and from muscle of patients with DMD shows increased expression of PDGFB in DMD muscle biopsy samples (E). Data are expressed as means \pm SD (E). $n=4$ per group (E). ${ }^{* *} P<0.01$ (t-test). Scale bars: $200 \mu \mathrm{m}(\mathbf{A}$ and $\mathbf{B}) ; 50 \mu \mathrm{m}(\mathbf{F}-\mathbf{N})$.

However, we also observed that many PDGF-BB fibers expressed developmental myosin, a known marker of regenerative fibers (Figure 2, C and D). To confirm this observation in vitro, we cultured myoblasts from controls and patients with DMD and differentiated them into myotubes. Using IF, we observed that myotubes expressed higher levels of PDGF-BB than did myoblasts (Figure 2, E-J). A significant increase in mRNA levels of $P D G F B$ in 

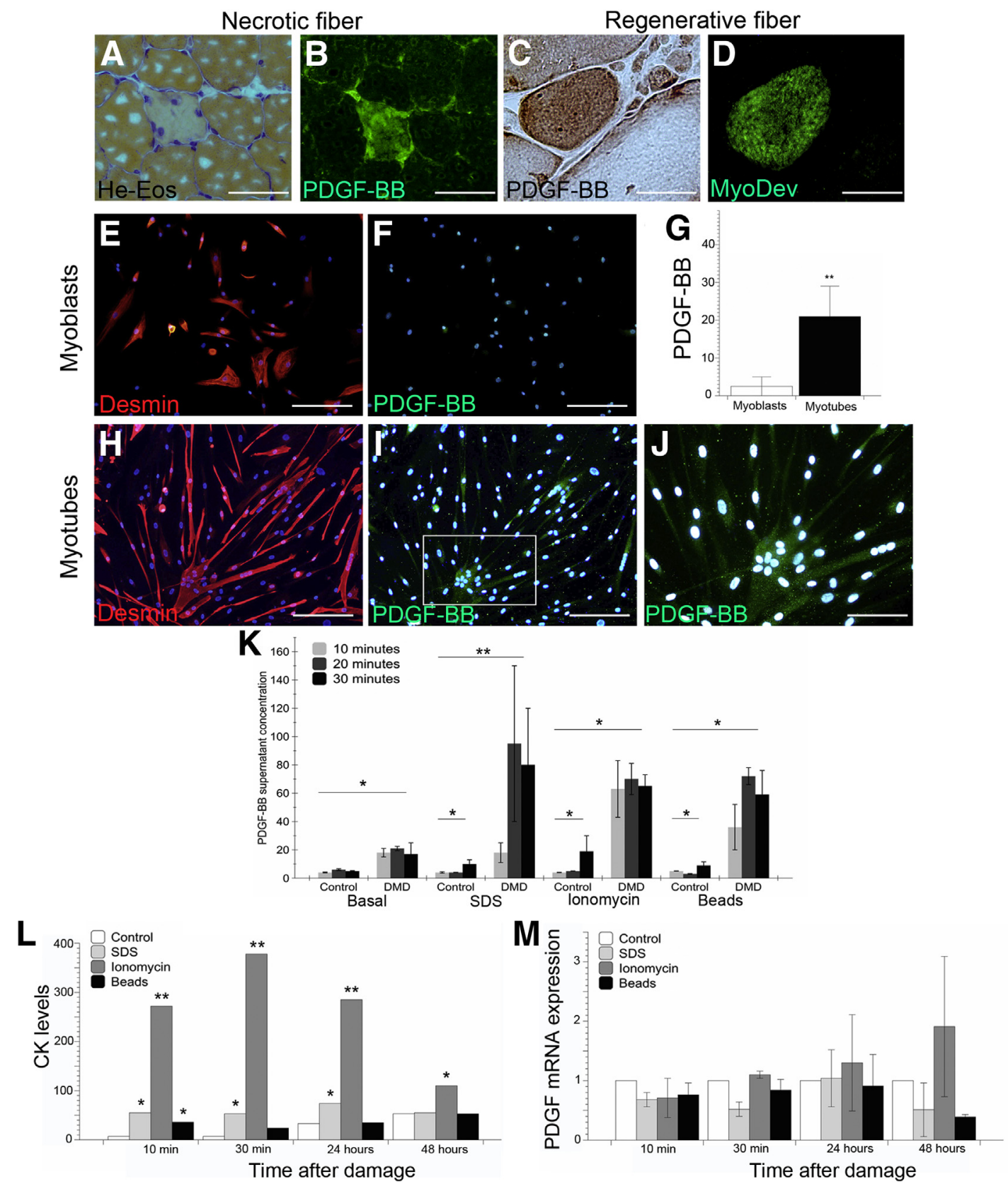

Figure 2 Regenerating and necrotic myofibers and myotubes express platelet-derived growth factor (PDGF)-BB. A-D: PDGF-BB is expressed in vivo by necrotic fibers (A and $\mathbf{B}$ ) and by regenerative developmental myosin (MyoDev)-positive fibers (C and $\mathbf{D}$ ). PDGF-BB is more highly expressed in myotubes compared with undifferentiated myoblasts. E-J: Double immunofluorescence shows expression of PDGF-BB by multinucleated myotubes $(\mathbf{H}-\mathbf{J})$ but not in nondifferentiated myoblasts ( $\mathbf{E}$ and $\mathbf{F}$ ) (the boxed region from $\mathbf{I}$ is detailed in $\mathbf{J}$ ). Relative quantification of $P D G F B$ mRNA in healthy skeletal muscle cultures shows a 33-fold increase in PDGFB in myotubes compared with controls (G). K: Expression of PDGF-BB by enzyme-linked immunosorbent assay in supernatants of myotubes obtained from DMD patients and controls after the induction of a chemical (SDS and ionomycin) or a physical (glass beads) injury. L: Quantification of creatine kinase levels in supernatants of control damaged myotubes 10 and 30 minutes and 24 and 48 minutes after damage. M: Relative quantification of PDGFB mRNA in damaged myotube cultures obtained from control patients. Data are expressed as means $\pm \mathrm{SD}(\mathbf{G}, \mathbf{K}$, and $\mathbf{M}) . n=5(\mathbf{G}, \mathbf{K}$, and $\mathbf{L}) ; n=3$ DMD patients $(\mathbf{K}) .{ }^{*} P<0.05,{ }^{*} P<0.01$. Scale bars: $50 \mu \mathrm{m}(\mathbf{A}-\mathbf{D}) ; 200 \mu \mathrm{m}(\mathbf{E}, \mathbf{F}$, $\mathbf{H}$, and $\mathbf{I}) ; 100 \mu \mathrm{m}(\mathbf{J})$. He-Eos, hematoxylin and eosin.

myotubes compared with those in undifferentiated myoblasts was observed using qPCR $(n=3 ; P=0.045 ; t$-test $)$ (Figure 2G).

To investigate whether an injury can release PDGF-BB from inside muscle fibers, we induced a chemical injury (SDS and ionomycin) or a physical injury (glass beads) in myotubes obtained from the myoblasts of controls and DMD patients ( $n=3$ per group). We subsequently analyzed PDGF-BB concentrations in culture supernatants using enzyme-linked immunosorbent assay. We observed that the concentration of PDGF-BB was increased progressively in all samples after damage (Figure $2 \mathrm{~K}$ ). The 
increase was significantly greater $(P<0.05$; analysis of variance) and occurred earlier in the myotubes from DMD patients than in those from controls. Creatine kinase level in the supernatant of cultures was increased just after damage and returned to normal value at 48 hours after the initial lesion (Figure 2L). PDGFB mRNA, however, remained unchanged despite the damage (Figure $2 \mathrm{M}$ ).

PDGFR $\beta$ Is Expressed in Muscle Fibers, Pericytes, and Satellite Cells in Muscle Biopsy Samples from Patients with Muscular Dystrophies

It is well known that PDGF-BB has a paracrine effect on PDGFR $\beta^{+}$cells. ${ }^{6}$ For this reason, we analyzed which cells expressed PDGFR $\beta$ in muscle biopsy samples from controls and DMD patients ( $n=5$ per group). PDGFR $\beta$ was expressed in vessel wall (Figure 3A) in controls. We identified PDGR $\beta$ in vessel-associated cells (Figure 3, B-D) expressing neural/glial antigen 2 (Figure $3, \mathrm{E}-\mathrm{H}$ ) and smooth muscle actin (Figure 3, I-L). These cells might be pericytes, as they have been previously shown/demonstrated to express PDGFR $\beta .{ }^{8}$ In patients with DMD, we found that PDGFR $\beta$ was expressed in vessels and also in the sarcolemma (Figure 3, M-O) and sarcoplasm (Figure 3, M-O) of some muscle fibers (Figure $3 \mathrm{~B}$ ). Satellite cells expressing $\mathrm{CD}_{56}{ }^{+}$were also positive for PDGFR $\beta$ (Figure 3, P-V). Myoblasts isolated from muscle biopsy samples expressed PDGFR $\beta$ in culture (Supplemental Figure S2), supporting the results obtained in vivo. CD4 and CD68 cells did not express PDGFR $\beta$ in vivo in muscle biopsy samples from patients with DMD (Supplemental Figure S3).

\section{Injection of Notexin into Skeletal Muscle of Control Mice Increases Expression of Pdgf-BB}

Acute damage after injection of notexin or cardiotoxin in skeletal muscle has been widely studied. ${ }^{29}$ In wild-type muscle, we observed widespread necrotic fibers 24 hours after injection (Figure 4, A and B). After 3 days, inflammatory infiltrates coexisted with incipient regenerating fibers (Figure 4C), which were more prominent at 7 days (Figure 4D). At 21 days, muscle regeneration was complete (Figure 4E). Sequence of muscle damage in $m d x$ mice was similar, although there were some differences. Inflammatory infiltrates appeared earlier; at 24 hours, groups of necrotic fibers were undergoing phagocytosis (Figure 4, K and L). At 3 days, inflammatory cells coexisted with regenerating fibers (Figure $4 \mathrm{M}$ ), which were predominant at 7 days (Figure 4N). Pdgf-BB expression in skeletal muscle was clearly increased after damage (Figure 4, F-J). Muscle fibers [both necrotic (Figure 4, $\mathrm{H}$ and $\mathrm{Q}$ ) regenerant (Figure 4, I and R)] and inflammatory infiltrates produced Pdgf-BB. In control muscles, $P d g f b$ progressively increased, peaking at 3 days, which coincided with maximum inflammatory infiltration and with the start of the regeneration process (Figure $4 \mathrm{U}$ ). Then, Pdgfb levels decreased progressively and returned to normal values at 21 days, when skeletal muscle regeneration was completed. In $m d x$ mice, $P d g f b$ levels started increasing earlier (Figure $4 \mathrm{U}$ ). We observed a first peak at 24 days, which coincided with the inflammatory infiltration. The high levels persisted at 3 days, when many incipient regenerating fibers could be detected, and then it progressively decreased, returning to normal levels at 21 days after damage.

\section{Influence of PDGF-BB on Myoblast Proliferation, Chemotaxis, and Differentiation}

We analyzed the effects of PDGF-BB on proliferation, migration, and differentiation of myoblasts isolated from human skeletal muscles. PDGF-BB significantly increased the proliferation of myoblasts after 4 and 6 days of treatment at concentrations of $10 \mathrm{ng} / \mathrm{mL}$ both in proliferation medium enriched with FBS $(n=3 ; P=0.03$; analysis of variance) (Figure 5A) and in more demanding culture conditions, such as a medium containing only $1 \%$ FBS and PDGF-BB $(P=0.02$; analysis of variance) (Figure $5 \mathrm{~B})$. Nintedanib completely reversed the effect of PDGF-BB on myoblast proliferation (Figure 5, A and B). PDGF-BB did not have any effect on the differentiation of myoblasts to myotubes. We detected a variation in neither the differentiation ratio nor in the number of nuclei per myotube after adding 10 or $50 \mathrm{ng} / \mathrm{mL}$ PDGF-BB to the culture medium (Figure 5, C and $\mathrm{D}$ and $\mathrm{F}-\mathrm{H})$. Moreover, we did not observe differences in the mRNA levels of MYODI in myoblasts treated with 10 $\mathrm{ng} / \mathrm{mL}$ PDGF-BB for 24 hours (Figure 5E). PDGF-BB produced a statistically significant increase in the chemotaxis of myoblasts in a dose-dependent manner $(P<0.05$; $t$ test) (Figure 5I).

To explore the molecular basis of the biological effect produced by PDGF-BB on myoblasts, we studied the intracellular pathways activated by PDGF-BB after $15 \mathrm{mi}-$ nutes of treatment. We observed that $10 \mathrm{ng} / \mathrm{mL}$ of PDGFBB significantly increased phosphorylated (p)-AKT levels in myoblasts $(P=0.001 ; t$-test $)$, whereas it had no effect on the phosphorylation of ERK1/2 or STAT-1 (Figure 5, J and K). Nintedanib blocked phosphorylation of Akt after treatment with PDGF-BB.

\section{Treatment of $m d x$ Mice with PDGF-BB Enhances Muscle Regeneration}

We studied whether the treatment of $m d x$ mice with i.m. injections of PDGF-BB would induce an expansion of the satellite cell pool in vivo as a proof of principle. We treated four $m d x$ mice twice a week with i.m. injections of PDGFBB. After 1 month of treatment, muscles from PDGFBB-treated animals were clearly different from those of vehicle-treated mice. We observed a clear reduction in inflammatory infiltrates (Figure 6, A-D and $\mathrm{M}-\mathrm{P}$ ) in muscles treated with PDGF-BB compared with those in 

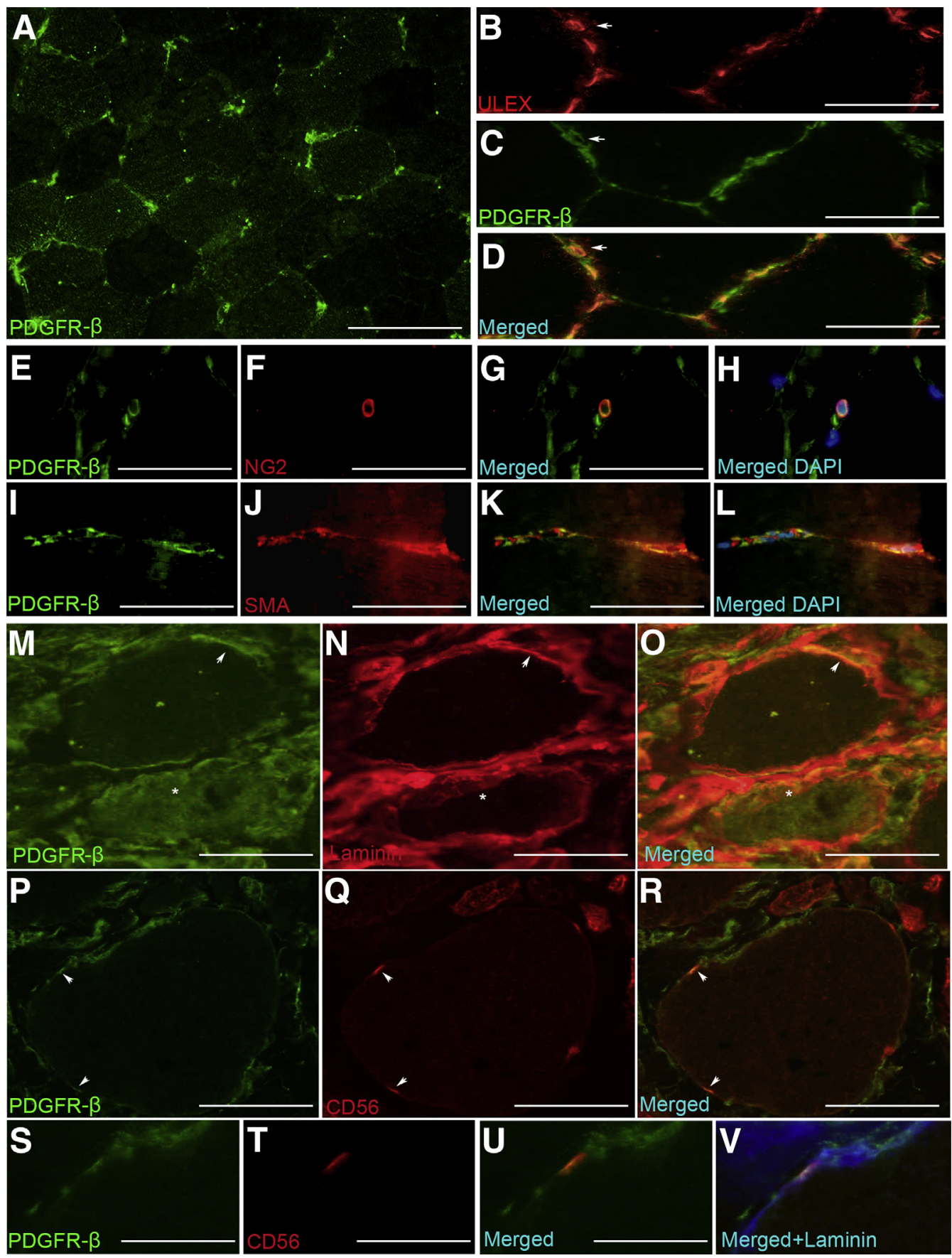

Figure 3 Platelet-derived growth factor receptor (PDGFR)- $\beta$ expression in control and dystrophic muscle biopsy samples. A-D: PDGFR- $\beta$ is expressed by perivascular cells in control muscle biopsy samples. Arrows in B-D show a PDGFR- $\beta^{+}$cell (C) close to a Ulex ${ }^{+}$capillary (B). E- 0: PDGFR- $\beta^{+}$cells coexpress neural/glial antigen $2(\mathbf{E}-\mathbf{H})$ and smooth muscle actin $(\mathbf{I}-\mathbf{L})$, probably being pericytes. In Duchenne muscle biopsy samples, sarcolemma and sarcoplasm in some muscle fibers were also stained $(\mathbf{M}-\mathbf{0})$. Arrows in $\mathbf{M}-\mathbf{0}$ show sarcolemma of a muscle fiber stained by laminin and PDGFR- $\beta^{+}$. Asterisks in $\mathbf{M}-\mathbf{0}$ show sarcoplasm of a muscle fiber stained with PDGFR- $\beta^{+}$. $\mathbf{P}-\mathbf{V}$ : Satellite cells co-express CD56 and PDGFR $\beta$ in Duchenne muscle dystrophy patients. Arrowheads in $\mathbf{P}-\mathbf{R}$ show two satellite cells co-expressing CD56 and PDGFR- $\beta^{+}$. Scale bars: $50 \mu \mathrm{m}(\mathbf{A}-\mathbf{D}) ; 200 \mu \mathrm{m}(\mathbf{E}-\mathbf{G}, \mathbf{I}$, $\mathbf{K}$, and $\mathbf{M}-\mathbf{U}) ; 100 \mu \mathrm{m}(\mathbf{J})$.

controls (nontreated) and vehicle-treated muscles. The population of $\mathrm{Pax}^{+}$satellite cells was increased significantly in muscle from PDGF-BB-treated $m d x$ mice compared with those from nontreated and vehicle-treated $m d x$ mice $(P=0.03 ; t$-test) (Figure 6, E-H). The increase in the population of satellite cells was associated with an increase in the number of regenerative muscle fibers $(11.8 \%$ in PDGF-BB-treated muscle versus $6.93 \%$ in vehicle-treated muscle $)(P=0.04 ; t$-test $)$ (Figure 6, I-L) and a reduction in the cross-sectional area of the fibers $(P=0.03 ; t$-test) (Figure 5D). Collagen I expression was not influenced by injection of PDGF-BB; 

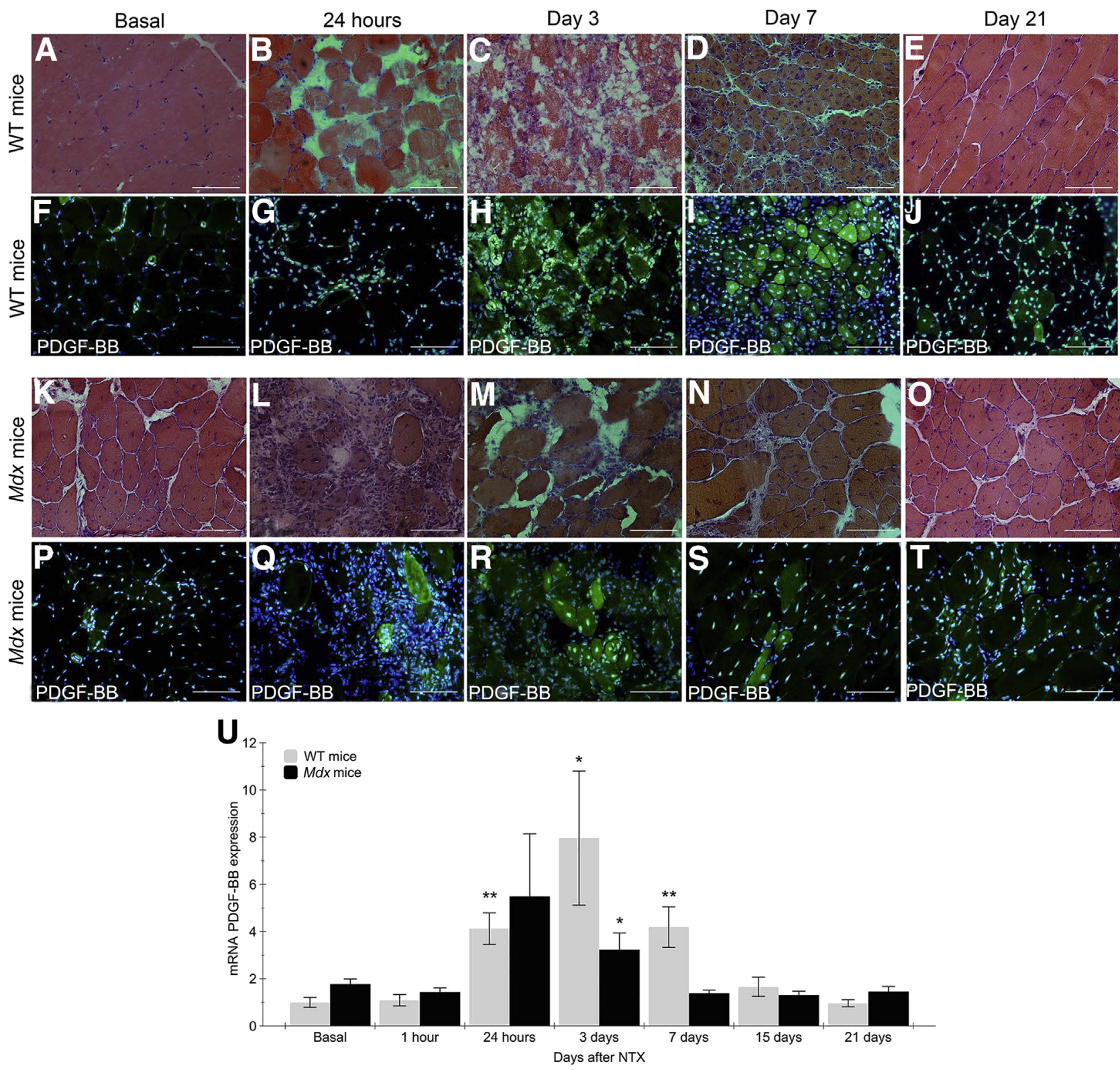

Figure 4 Study of platelet-derived growth factor (PDGF)-BB expression after acute damage produced by notexin in healthy $\mathrm{C57}$ and dystrophic $\mathrm{mdx}$ mouse models. $\mathbf{A}-\mathbf{T}$ : The panels show the process of muscle regeneration in healthy $\mathbf{C} 57(\mathbf{A}-\mathbf{J})$ and dystrophic $m d x(\mathbf{K}-\mathbf{T})$ mouse models after notexin injection. A-E: Hematoxylin and eosin (H\&E) staining. A: Muscle structure at baseline, before notexin injection. B: Necrotic fibers and normal fibers 24 hours after injection, with no inflammation. C: Widespread inflammatory infiltrates surrounding necrotic muscle fibers 3 days after injection. D: Several regenerating muscle fibers 7 days after injection, characterized by basophilic internal nuclei. E: Complete muscle regeneration 21 days after injection, but evidencing the presence of internal nuclei in many fibers. $\mathbf{F}-\mathbf{J}$ : PDGF-BB expression in muscles from control mice after notexin injection. F: Only vessels at baseline express PDGF-BB. G: PDGF-BB expression 24 hours after injection. H: PDGF-BB expression by necrotic fibers. I and J: Regenerative muscle fibers with internal nuclei express PDGF-BB. K-0: Muscle structure of $m d x$ mice after notexin injection (H\&E staining). K: Mild dystrophic changes. L: Inflammatory infiltrates surrounding necrotic fibers are clearly seen at 24 hours after injection. M: Scarce inflammatory infiltrates are still observed at 3 days and are associated to many small regenerative fibers. $\mathbf{N}$ : Regenerative fibers are clearly observed at 7 days. $\mathbf{0}$ : Complete muscle regeneration is detected, although muscle structure is clearly dystrophic at 21 days after injection. P-T: PDGF-BB expression studied using immunofluorescence in $m d x$ mice. P: PDGF-BB is expressed by vessels and some muscle fibers at baseline. Q: Necrotic fibers express PDGF-BB at 24 hours after notexin injection. $\mathbf{R}$ and S: Regenerative fibers express PDGF-BB at 3 and 7 days after the injection. T: At 21 days, PDGF-BB expression is evident in the sarcoplasm of some muscle fibers. Pdgfb levels increase after muscle damage in both animal models. In C57 mice, levels peak at 3 days, whereas in the $m d x$ mice, $P d g f b$ levels reach the maximum at 24 hours. U: In both cases, Pdgfb levels return to normal basal levels at 21 days after muscle damage. Data are expressed as means \pm SD (U). $n=3$ (U). ${ }^{*} P<0.05,{ }^{* *} P<0.01$. Scale bars $=100 \mu \mathrm{m}$. NTX, notexin; WT, wild type.

we did not detect significant changes in the area covered by collagen I in muscle tissue and we did not observe differences in the expression of collagen I using Western blot analysis (Supplemental Figure S4).

\section{Discussion}

Our study demonstrates that PDGF-BB may influence the process of muscle regeneration in patients with DMD. We 
A
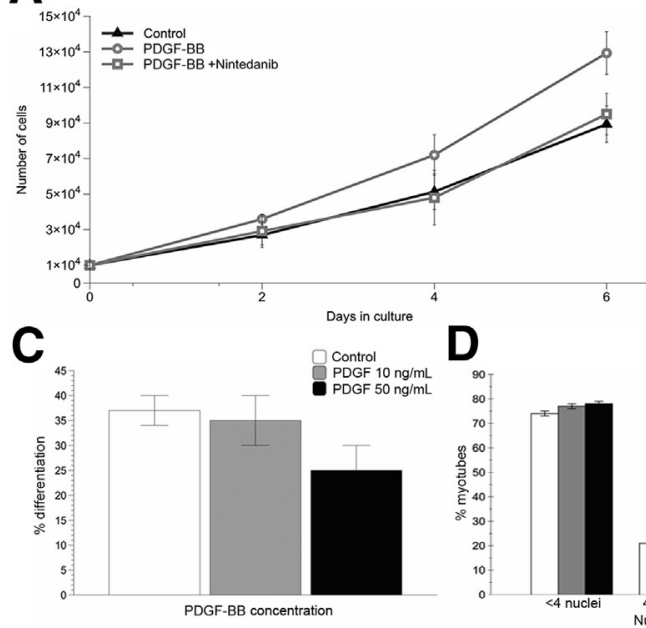

B

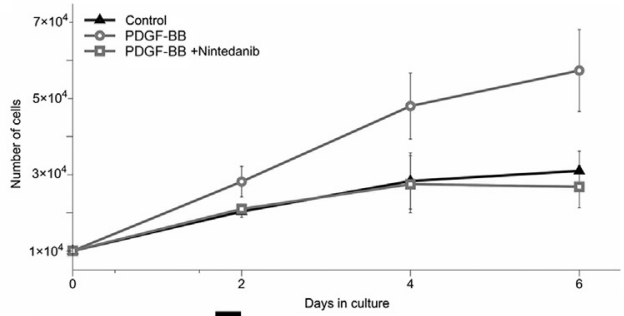

E

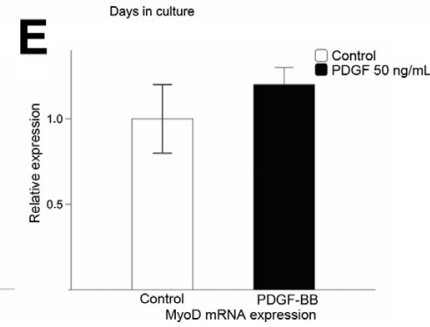

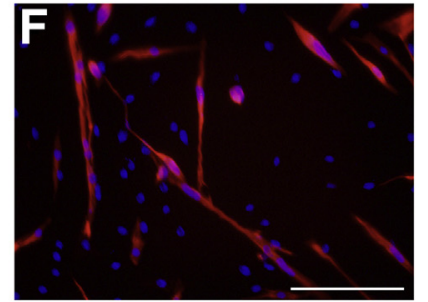

|

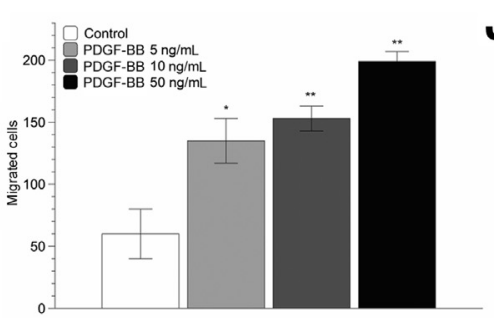

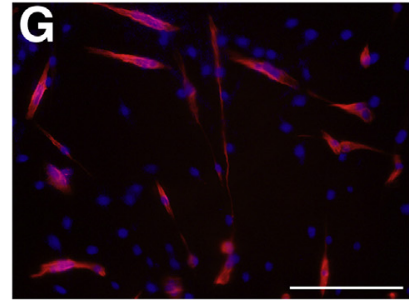
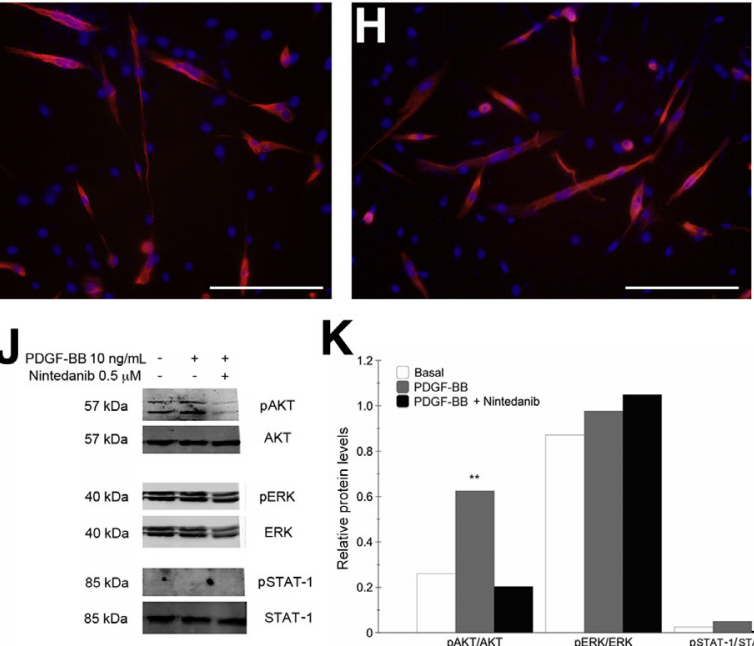

$\mathbf{K}_{12}$

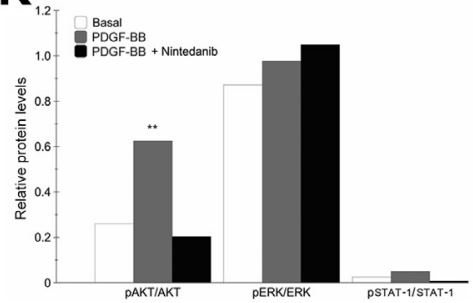

Figure 5 Functional effect of platelet-derived growth factor (PDGF)-BB on myoblasts in culture. A and B: PDGF-BB enhances proliferation of myoblasts both in $20 \%$ enriched proliferation medium (A) and in low serum (1\% fetal bovine serum) conditions (B). Significant differences are observed at days 4 and 6 of culture in both cases. C and D: PDGF-BB does not have any effect on the differentiation of myoblasts to myotubes using the following parameters: differentiation ratio (C) and mean number of nuclei per myotube (D). E: Expression of MyoDin myoblasts treated with PDGF for 24 hours is not significantly different from that observed in nontreated myoblasts ( $t$-test). $\mathbf{F}-\mathbf{H}$ : Myotubes cultured in a differentiation medium not enriched with PDGF-BB (F), cultured in a medium enriched with $10 \mathrm{ng} / \mathrm{mL}$ PDGF-BB (G), and cultured in a medium enriched with $50 \mathrm{ng} / \mathrm{mL}$ PDGF-BB (H). I: PDGF-BB enhances chemotaxis of myoblasts in a dose-dependent manner ( $t$-test). $\mathbf{J}$ and $\mathbf{K}$ : PDGF-BB activates protein kinase B (AKT) phosphorylation in myoblasts but does not have any effect on phosphorylation of ERK or STAT-1. Data are expressed as means \pm SD $(\mathbf{C}-\mathbf{E}, \mathbf{I}) . n=3(\mathbf{A}-\mathbf{E}$, I, and $\mathbf{K}) .{ }^{*} P<0.05,{ }^{*} P<0.01 . P<0.05[\mathrm{~B}$, days 4 and 6 ( $t$ test)]. Scale bars $=50 \mu \mathrm{m}(\mathbf{F}-\mathbf{H})$. Myod, myogenic differentiation 1.

base our conclusion on the following key results: i) PDGF-BB was secreted by necrotic and regenerative fibers and by inflammatory infiltrates in muscle biopsy samples from patients with DMD; ii) myotubes expressed higher levels of PDGF-BB than did undifferentiated myoblasts in culture; iii) secretion of PDGF-BB from damaged mature myotubes after chemical and physical damage was detected; iv) PDGF-BB expression in notexin-injured muscle was clearly increased, coinciding with infiltration of inflammatory cells and muscle regeneration; v) PDGF-BB activated myoblasts, inducing their proliferation and migration; and vi) treatment of $m d x$ mice with i.m. injections of PDGF-BB increased the population of satellite cells and the number of regenerative fibers.

We previously reported that the population of satellite cells increases in biopsy samples from patients with DMD and Becker muscle dystrophy. ${ }^{30}$ To determine which factors could influence this increase, we studied PDGFs because they have been related to the proliferation of several mesenchymal cells. ${ }^{23,31}$ We found that PDGF-BB was the member of the PDGF family that displayed the highest level of expression in muscle biopsy samples from DMD patients (data not shown). Zhao et $\mathrm{al}^{17}$ had already reported an increased expression of PDGF-BB in muscle fibers from DMD patients, although their results were based only in IF 

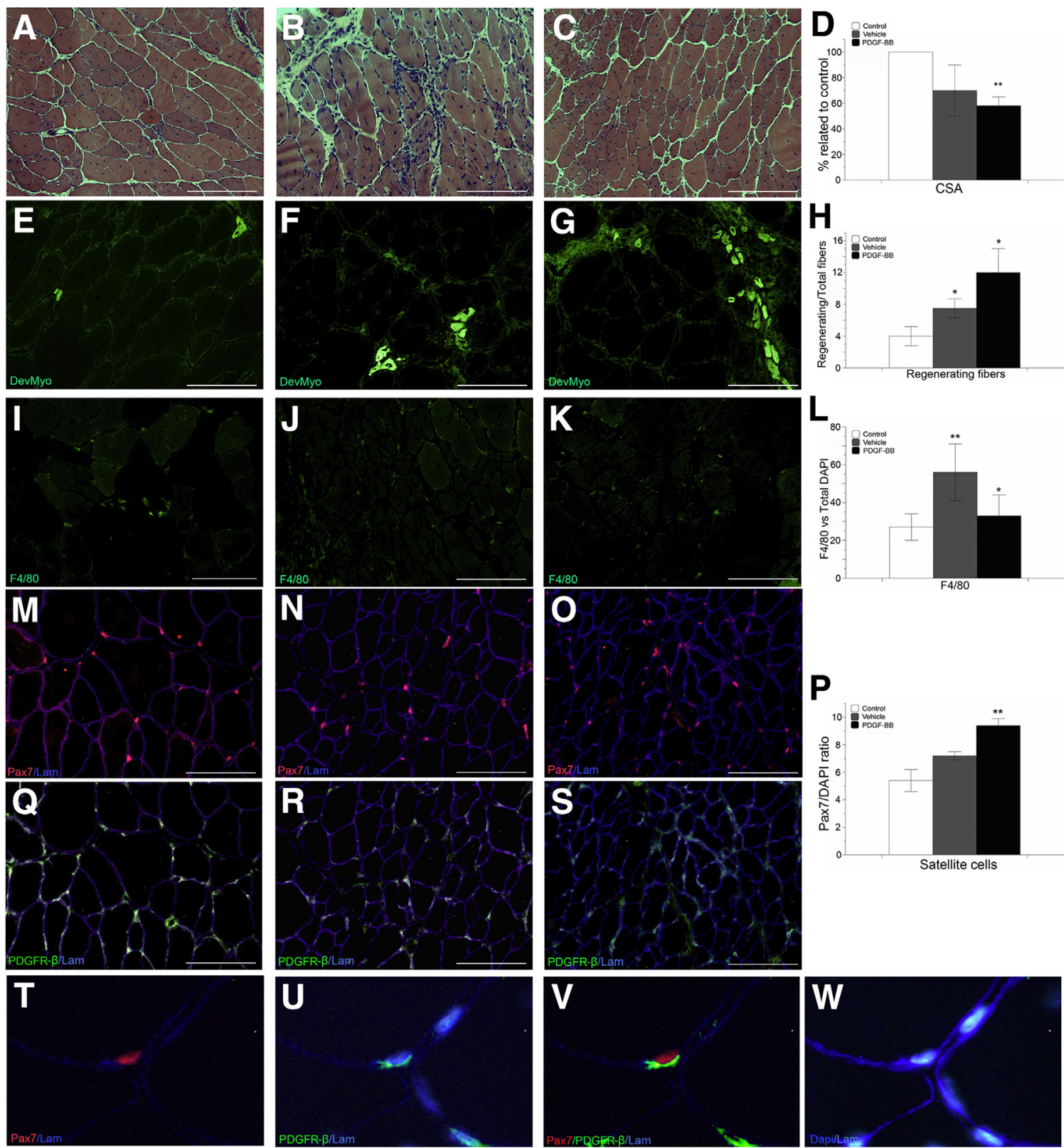

Figure 6 Treatment of $m d x$ mice with platelet-derived growth factor (PDGF)-BB enhances muscle regeneration and proliferation of satellite cells and pericytes. A-C: Muscle from $m d x$ mice treated with an i.m. injection of PDGF-BB show significant histologic changes compared with vehicle-treated muscle. More regenerative fibers that are smaller, and fewer inflammatory cells, are observed. D: Cross-sectional area of muscle fibers is smaller in PDGF-BB-treated muscles. E-H: The number of developmental myosin (DevMyo)-expressing fibers is significantly increased in PDGF-BB-treated muscles compared with nontreated (control) muscles and vehicle-treated muscles. I-L: The population of inflammatory cells invading muscles treated with PDGF-BB decreases compared with that in vehicle-treated muscles. M-P: The population of paired box 7 protein (Pax7) satellite cells significantly increases in PDGF-BB-treated muscles compared with that in nontreated muscles and vehicle-treated muscles. Q-V: Most of the Pax $7^{+}$cells also express PDGF receptor (PDGFR)- $\beta$. Data are expressed as means \pm SD (D, H, L, and $\left.\mathbf{P}\right) . n=4$ per group $(\mathbf{D}, \mathbf{H}, \mathbf{L}$, and $\mathbf{P}) .{ }^{*} P<0.05 ;{ }^{*} P<0.01$. Scale bars $=50 \mu \mathrm{m}$. Original magnification: $\times 400(\mathbf{T}-\mathbf{W})$. Lam, laminin.

and were not confirmed using Western blot analysis, qPCR, or in vitro studies as we performed in our study. We observed that PDGF-BB ${ }^{+}$muscle fibers expressed markers of muscle regeneration, such as developmental myosin, suggesting that PDGF-BB could have an effect in the process of muscle regeneration in vivo. Our in vitro results supported this hypothesis: $P D G F B$ increased during differentiation from myoblast to myotubes. Moreover, we have observed that PDGF-BB is quickly released by myotubes after chemical or physical damage and then can activate surrounding cells. We have also observed that many necrotic fibers expressed PDGF-BB in vivo, suggesting that PDGF-BB could function as a regeneration signal released by fibers after injury, as described in other tissues such as bone or liver. ${ }^{32,33}$ The results of our notexin-induced muscle damage support this fact. PDGF-BB expression was clearly increased after acute damage, coinciding with the inflammatory infiltrate and the start of the regeneration process 
mimicking that has been described with other well-known promitotic factors, such as hepatic growth factor, fibroblast growth factor, and insulin growth factor. ${ }^{29,34,35}$ PDGFs act primarily as paracrine growth factors, so it is likely that the release of PDGF-BB from regenerating muscle fibers has an effect on surrounding cells expressing PDGFR $\beta$, such as pericytes or satellite cells. ${ }^{36,37}$

Satellite cells in a quiescent state are located beneath the basal lamina of healthy muscle fibers. ${ }^{5,36}$ After damage, satellite cells are activated and then proliferate and differentiate into myoblasts, fusing to injured muscle fibers and contributing to muscle regeneration. ${ }^{38}$ Satellite cells are activated in response to several signals from regenerative microenvironment, such as adhesion molecules, necrotic cues released from damaged fibers, and growth factors and cytokines produced by neighboring cells. Several growth factors, including hepatic growth factor, fibroblast growth factor, IL-1, IL-6, insulin growth factor, influence the proliferation of satellite cells. ${ }^{39-42}$ It is well known that PDGFs are potent mitogens for a variety of mesenchymal cell types. ${ }^{6}$ It has been previously described that PDGF-BB enhances the proliferation of myoblasts obtained from several animal species, such as the mouse, rat, and chicken. ${ }^{24-26}$ We have observed a homologous effect in human myoblasts. The fact that this process seems to be conserved along the vertebrate lineage, supports an important role of PDGF-BB in proliferation of satellite cells. Phosphorylation of PDGFR $\beta$ activates several well-characterized intracellular signaling pathways such as MAPK/ERK, phosphoinositide 3-kinase/Akt, and protein kinase $\mathrm{C}$, which are known to be involved in multiple cellular responses. ${ }^{43}$ Some of these pathways, including Akt, ERK1/2, and STATs, have also been involved in the proliferation of myoblasts. ${ }^{4-46}$ Here, we observed that PDGF-BB enhanced Akt phosphorylation, but in contrast it had no effect on the MAPK/ERK or Janus kinase (JAK)/STAT pathway.

To differentiate and fuse into damaged fibers, proliferating myoblasts must migrate and establish stable cell contact. ${ }^{47}$ Cell migration is therefore essential for adult muscle repair. The effect of several factors on myoblast migration has been previously studied, yet the process of cell migration is not completely understood. PDGF-BB has a well-characterized role in the migration of many different mesenchymal cells during organogenesis and in disease. $^{6,13,48}$ In the case of skeletal muscle, PDGF-BB orchestrates the migration of murine embryonic myoblasts from somites toward the limb. ${ }^{49}$ Hereby we have shown that PDGF-BB enhanced satellite cell migration in vitro in a dose-dependent manner. Based on our observations it is tempting to hypothesize that PDGF-BB released by regenerating muscle fibers activates satellite cell proliferation and migration of these cells toward muscle fibers.

We have observed that PDGF-BB does not have any effect on the differentiation of myoblasts in vitro. It has been previously reported that PDGF-BB delayed and decreased the differentiation process of myoblasts in vitro. ${ }^{24,50}$ However, Jin et al ${ }^{24,50}$ reported that PDGFR mRNA rapidly decreased once differentiation of rat myoblasts started, suggesting that PDGF-BB acts only on proliferating myoblasts and not on myoblasts undergoing differentiation in vitro. Our results support this hypothesis; we did not observe any effect in the differentiation index of myoblasts in vitro. In contrast, we observed that treatment of $m d x$ mice with repeated i.m. injections of PDGF-BB increased the number of satellite cells, confirming the positive effect on proliferation of PDGF-BB. Consequently, the number of regenerative fibers increased, suggesting that PDGF-BB did not decrease the ability of satellite cells to differentiate in vivo.

We confirmed our in vitro results with an in vivo model of DMD as a proof-of-principle approach. We observed that the treatment of $m d x$ mice with repeated i.m. injections of PDGF-BB produced increases in the population of satellite cells and in the number of regenerative fibers. Inflammatory infiltrates were also reduced and muscle tissue fibrosis did not increase. These observations demonstrate that PDGF-BB could promote muscle regeneration in a murine model of DMD. Muscle degeneration in patients with muscular dystrophies is a complex process produced by the confluence of different factors. ${ }^{51}$ On one hand there is an expansion of fibrotic tissue; on the other hand there is an impairment of the regenerative process of skeletal muscle. It is well known that proinflammatory invading macrophages continuously release profibrotic growth factors, such as transforming growth factor $\beta$ and PDGF-AA, which activates PDFR $\alpha^{+}$ fibro-adipogenic progenitor cells, enhancing the expansion of fibrotic tissue. ${ }^{4,17,52}$ Tyrosine kinase inhibitor drugs, such as imatinib or crenolanib, block phosphorylation of several cell receptors, including PDGFRs. These drugs have shown effectiveness in reducing fibrosis and accordingly improving muscle function. ${ }^{21,22,53}$ Based on our results, we could hypothesize that tyrosine kinase inhibitors may impair muscle regeneration by blocking the effects of PDGF-BB on satellite cells. This concept has not been studied in any of the reports published. However, satellite cell proliferation does not depend only on the effects of PDGF-BB; other growth factors such as IL-6, hepatic growth factor, and stromal cell-derived factor 1 influence it. ${ }^{36}$ None of them are blocked by tyrosine kinase inhibitor; therefore, expansion of satellite cells in a tyrosine kinase-treated animal model may not be compromised. It has also been suggested that damaged muscle fibers could express factors that promote muscle regeneration. ${ }^{54,55}$ Hereby we present data supporting a role of PDGF-BB released by muscle fibers as a proregenerative factor in patients with DMD.

In conclusion, our results support the hypothesis that PDGF-BB would be released by muscle fibers to promote muscle regeneration in dystrophic muscles by activating the proliferation and migration of satellite cells to injured 
muscle fibers. Based on our results, we propose that treatment with agonists of PDGFR $\beta$ in animal models of muscular dystrophy may result in an improvement in muscle regeneration and, consequently, a reduction in muscle loss.

\section{Acknowledgments}

We thank Miquel Navas for technical support with the experiments and Luis Querol, Sonia Segovia, Juan Jesus Vilchez, Carolyn Newey, Sergi Martinez-Ramirez, and Sara DeGregorio for editorial comments.

P.P.-J., N.d.L., and X.S.-C. designed and performed experiments, collected and analyzed data, and wrote the manuscript; E.G. and J.D.-M. designed the experiments, analyzed data, wrote the manuscript, and provided funding; C.S.-R. designed the experiments, analyzed data, and wrote the manuscript; E.F.-S. and C.G. performed experiments, collected and analyzed data, and wrote the manuscript; and I.I. performed experiments, wrote the manuscript, and provided funding.

\section{Supplemental Data}

Supplemental material for this article can be found at http://dx.doi.org/10.1016/j.ajpath.2017.04.011.

\section{References}

1. Bushby K, Finkel R, Birnkrant DJ, Case LE, Clemens PR, Cripe L, Kaul A, Kinnett K, McDonald C, Pandya S, Poysky J, Shapiro F, Tomezsko J, Constantin C; DMD Care Considerations Working Group: Diagnosis and management of Duchenne muscular dystrophy, part 1: diagnosis, and pharmacological and psychosocial management. Lancet Neurol 2010, 9:77-93

2. Wallace GQ, McNally EM: Mechanisms of muscle degeneration, regeneration, and repair in the muscular dystrophies. Annu Rev Physiol 2009, 71:37-57

3. Saccone V, Consalvi S, Giordani L, Mozzetta C, Barozzi I, Sandona M, Ryan T, Rojas-Munoz A, Madaro L, Fasanaro P, Borsellino G, De Bardi M, Frige G, Termanini A, Sun X, Rossant J, Bruneau BG, Mercola M, Minucci S, Puri PL: HDAC-regulated myomiRs control BAF60 variant exchange and direct the functional phenotype of fibro-adipogenic progenitors in dystrophic muscles. Genes Dev 2014, 28:841-857

4. MacDonald EM, Cohn RD: TGFbeta signaling: its role in fibrosis formation and myopathies. Curr Opin Rheumatol 2012, 24:628-634

5. Tedesco FS, Dellavalle A, Diaz-Manera J, Messina G, Cossu G: Repairing skeletal muscle: regenerative potential of skeletal muscle stem cells. J Clin Invest 2010, 120:11-19

6. Andrae J, Gallini R, Betsholtz C: Role of platelet-derived growth factors in physiology and medicine. Genes Dev 2008, 22:1276-1312

7. Heldin CH, Westermark B: Mechanism of action and in vivo role of platelet-derived growth factor. Physiol Rev 1999, 79:1283-1316

8. Dellavalle A, Sampaolesi M, Tonlorenzi R, Tagliafico E, Sacchetti B, Perani L, Innocenzi A, Galvez BG, Messina G, Morosetti R, Li S, Belicchi M, Peretti G, Chamberlain JS, Wright WE, Torrente Y, Ferrari S, Bianco P, Cossu G: Pericytes of human skeletal muscle are myogenic precursors distinct from satellite cells. Nat Cell Biol 2007, 9:255-267
9. Trojanowska M: Role of PDGF in fibrotic diseases and systemic sclerosis. Rheumatology 2008, 47(Suppl 5):v2-v4

10. Tallquist M, Kazlauskas A: PDGF signaling in cells and mice. Cytokine Growth Factor Rev 2004, 15:205-213

11. Li X, Ponten A, Aase K, Karlsson L, Abramsson A, Uutela M, Backstrom G, Hellstrom M, Bostrom H, Li H, Soriano P, Betsholtz C, Heldin $\mathrm{CH}$, Alitalo $\mathrm{K}$, Ostman A, Eriksson U: PDGF-C is a new protease-activated ligand for the PDGF alpha-receptor. Nat Cell Biol 2000, 2:302-309

12. Enge $M$, Bjarnegard $M$, Gerhardt $H$, Gustafsson E, Kalen M, Asker N, Hammes HP, Shani M, Fassler R, Betsholtz C: Endothelium-specific platelet-derived growth factor-B ablation mimics diabetic retinopathy. EMBO J 2002, 21:4307-4316

13. Armulik A, Abramsson A, Betsholtz C: Endothelial/pericyte interactions. Circ Res 2005, 97:512-523

14. Gallini R, Lindblom P, Bondjers C, Betsholtz C, Andrae J: PDGF-A and PDGF-B induces cardiac fibrosis in transgenic mice. Exp Cell Res 2016, 349:282-290

15. Hu W, Huang Y: Targeting the platelet-derived growth factor signalling in cardiovascular disease. Clin Exp Pharmacol Physiol 2015, 42:1221-1224

16. Appiah-Kubi K, Wang Y, Qian H, Wu M, Yao X, Wu Y, Chen Y: Platelet-derived growth factor receptor/platelet-derived growth factor (PDGFR/PDGF) system is a prognostic and treatment response biomarker with multifarious therapeutic targets in cancers. Tumour Biol 2016, 37:10053-10066

17. Zhao Y, Haginoya K, Sun G, Dai H, Onuma A, Iinuma K: Plateletderived growth factor and its receptors are related to the progression of human muscular dystrophy: an immunohistochemical study. J Pathol 2003, 201:149-159

18. Joe AW, Yi L, Natarajan A, Le Grand F, So L, Wang J, Rudnicki MA, Rossi FM: Muscle injury activates resident fibro/adipogenic progenitors that facilitate myogenesis. Nat Cell Biol 2010, $12: 153-163$

19. Uezumi A, Fukada S, Yamamoto N, Takeda S, Tsuchida K: Mesenchymal progenitors distinct from satellite cells contribute to ectopic fat cell formation in skeletal muscle. Nat Cell Biol 2010, 12:143-152

20. Olson LE, Soriano P: Increased PDGFRalpha activation disrupts connective tissue development and drives systemic fibrosis. Dev Cell 2009, 16:303-313

21. Huang P, Zhao XS, Fields M, Ransohoff RM, Zhou L: Imatinib attenuates skeletal muscle dystrophy in mdx mice. FASEB J 2009, 23: $2539-2548$

22. Ieronimakis N, Hays A, Prasad A, Janebodin K, Duffield JS, Reyes M: PDGFRalpha signalling promotes fibrogenic responses in collagen-producing cells in Duchenne muscular dystrophy. J Pathol 2016, 240:410-424

23. Armulik A, Genove G, Betsholtz C: Pericytes: developmental, physiological, and pathological perspectives, problems, and promises. Dev Cell 2011, 21:193-215

24. Jin P, Sejersen T, Ringertz NR: Recombinant platelet-derived growth factor-BB stimulates growth and inhibits differentiation of rat L6 myoblasts. J Biol Chem 1991, 266:1245-1249

25. Yablonka-Reuveni Z, Seifert RA: Proliferation of chicken myoblasts is regulated by specific isoforms of platelet-derived growth factor: evidence for differences between myoblasts from mid and late stages of embryogenesis. Dev Biol 1993, 156:307-318

26. Yablonka-Reuveni Z, Balestreri TM, Bowen-Pope DF: Regulation of proliferation and differentiation of myoblasts derived from adult mouse skeletal muscle by specific isoforms of PDGF. J Cell Biol 1990, 111:1623-1629

27. Diaz-Manera J, Touvier T, Dellavalle A, Tonlorenzi R, Tedesco FS, Messina G, Meregalli M, Navarro C, Perani L, Bonfanti C, Illa I, Torrente Y, Cossu G: Partial dysferlin reconstitution by adult murine mesoangioblasts is sufficient for full functional recovery in a murine model of dysferlinopathy. Cell Death Dis 2010, 1:e61 
28. de Luna N, Gallardo E, Soriano M, Dominguez-Perles R, de la Torre C, Rojas-Garcia R, Garcia-Verdugo JM, Illa I: Absence of dysferlin alters myogenin expression and delays human muscle differentiation "in vitro". J Biol Chem 2006, 281:17092-17098

29. Hardy D, Besnard A, Latil M, Jouvion G, Briand D, Thepenier C, Pascal Q, Guguin A, Gayraud-Morel B, Cavaillon JM, Tajbakhsh S, Rocheteau P, Chretien F: Comparative study of injury models for studying muscle regeneration in mice. PLoS One 2016, 11:e0147198

30. Diaz-Manera J, Gallardo E, de Luna N, Navas M, Soria L, Garibaldi M, Rojas-Garcia R, Tonlorenzi R, Cossu G, Illa I: The increase of pericyte population in human neuromuscular disorders supports their role in muscle regeneration in vivo. J Pathol 2012, 228: $544-553$

31. Nazari M, Ni NC, Ludke A, Li SH, Guo J, Weisel RD, Li RK: Mast cells promote proliferation and migration and inhibit differentiation of mesenchymal stem cells through PDGF. J Mol Cell Cardiol 2016, 94: $32-42$

32. Hankenson KD, Gagne K, Shaughnessy M: Extracellular signaling molecules to promote fracture healing and bone regeneration. Adv Drug Deliv Rev 2015, 94:3-12

33. Adas G, Koc B, Adas M, Duruksu G, Subasi C, Kemik O, Kemik A, Sakiz D, Kalayci M, Purisa S, Unal S, Karaoz E: Effects of mesenchymal stem cells and VEGF on liver regeneration following major resection. Langenbecks Arch Surg 2016, 401:725-740

34. Liu X, Liu Y, Zhao L, Zeng Z, Xiao W, Chen P: Macrophage depletion impairs skeletal muscle regeneration: the roles of regulatory factors for muscle regeneration. Cell Biol Int 2017, 41:228-238

35. Tatsumi R, Anderson JE, Nevoret CJ, Halevy O, Allen RE: HGF/SF is present in normal adult skeletal muscle and is capable of activating satellite cells. Dev Biol 1998, 194:114-128

36. Yin H, Price F, Rudnicki MA: Satellite cells and the muscle stem cell niche. Physiol Rev 2013, 93:23-67

37. Dellavalle A, Maroli G, Covarello D, Azzoni E, Innocenzi A, Perani L, Antonini S, Sambasivan R, Brunelli S, Tajbakhsh S, Cossu G: Pericytes resident in postnatal skeletal muscle differentiate into muscle fibres and generate satellite cells. Nat Commun 2011, 2:499

38. Joanisse S, Parise G: Cytokine mediated control of muscle stem cell function. Adv Exp Med Biol 2016, 900:27-44

39. Miller KJ, Thaloor D, Matteson S, Pavlath GK: Hepatocyte growth factor affects satellite cell activation and differentiation in regenerating skeletal muscle. Am J Physiol Cell Physiol 2000, 278: C174-C181

40. Kastner S, Elias MC, Rivera AJ, Yablonka-Reuveni Z: Gene expression patterns of the fibroblast growth factors and their receptors during myogenesis of rat satellite cells. J Histochem Cytochem 2000, 48:1079-1096

41. Han B, Tong J, Zhu MJ, Ma C, Du M: Insulin-like growth factor-1 (IGF-1) and leucine activate pig myogenic satellite cells through mammalian target of rapamycin (mTOR) pathway. Mol Reprod Dev 2008, 75:810-817
42. Allen RE, Boxhorn LK: Regulation of skeletal muscle satellite cell proliferation and differentiation by transforming growth factor-beta, insulin-like growth factor I, and fibroblast growth factor. J Cell Physiol 1989, 138:311-315

43. Farooqi AA, Siddik ZH: Platelet-derived growth factor (PDGF) signalling in cancer: rapidly emerging signalling landscape. Cell Biochem Funct 2015, 33:257-265

44. Jones NC, Fedorov YV, Rosenthal RS, Olwin BB: ERK1/2 is required for myoblast proliferation but is dispensable for muscle gene expression and cell fusion. J Cell Physiol 2001, 186:104-115

45. Ho TC, Chiang YP, Chuang CK, Chen SL, Hsieh JW, Lan YW, Tsao YP: PEDF-derived peptide promotes skeletal muscle regeneration through its mitogenic effect on muscle progenitor cells. Am J Physiol Cell Physiol 2015, 309:C159-C168

46. Barzilai-Tutsch H, Bodanovsky A, Maimon H, Pines M, Halevy O: Halofuginone promotes satellite cell activation and survival in muscular dystrophies. Biochim Biophys Acta 2016, 1862:1-11

47. Goetsch KP, Myburgh KH, Niesler CU: In vitro myoblast motility models: investigating migration dynamics for the study of skeletal muscle repair. J Muscle Res Cell Motil 2013, 34:333-347

48. Andrae N, Kirches E, Hartig R, Haase D, Keilhoff G, Kalinski T, Mawrin C: Sunitinib targets PDGF-receptor and Flt3 and reduces survival and migration of human meningioma cells. Eur J Cancer 2012, 48:1831-1841

49. Webb SE, Lee KK: Effect of platelet-derived growth factor isoforms on the migration of mouse embryo limb myogenic cells. Int J Dev Biol 1997, 41:597-605

50. Yablonka-Reuveni Z, Rivera AJ: Influence of PDGF-BB on proliferation and transition through the MyoD-myogenin-MEF2A expression program during myogenesis in mouse C2 myoblasts. Growth Factors 1997, 15:1-27

51. Tabebordbar M, Wang ET, Wagers AJ: Skeletal muscle degenerative diseases and strategies for therapeutic muscle repair. Annu Rev Pathol 2013, 8:441-475

52. Burks TN, Cohn RD: Role of TGF-beta signaling in inherited and acquired myopathies. Skelet Muscle 2011, 1:19

53. Lemos DR, Babaeijandaghi F, Low M, Chang CK, Lee ST, Fiore D, Zhang RH, Natarajan A, Nedospasov SA, Rossi FM: Nilotinib reduces muscle fibrosis in chronic muscle injury by promoting TNFmediated apoptosis of fibro/adipogenic progenitors. Nat Med 2015, 21:786-794

54. Conboy IM, Conboy MJ, Smythe GM, Rando TA: Notch-mediated restoration of regenerative potential to aged muscle. Science 2003, 302:1575-1577

55. Ratajczak MZ, Majka M, Kucia M, Drukala J, Pietrzkowski Z, Peiper S, Janowska-Wieczorek A: Expression of functional CXCR4 by muscle satellite cells and secretion of SDF-1 by muscle-derived fibroblasts is associated with the presence of both muscle progenitors in bone marrow and hematopoietic stem/progenitor cells in muscles. Stem Cells 2003, 21:363-371 